\title{
La deuda externa y los pobres
}

Mario Zañartu S. J. *

\section{LOS SINTOMAS Y SUS CAUSAS}

James Grant, director general de la UNICEF, asegura que el efecto directo de la deuda externa sobre la vida de los niños es equivalente a que cayese un Jumbo lleno de niños por día, y muriesen todos.

« ¿Es meramente una cuestión retórica preguntar cuántos lactantes y niños mueren cada día en Africa debido a que los recursos están siendo acaparados por el reembolso de la deuda?»; palabras del Papa Juan Pablo II en Lusaka, Zambia, 3 de mayo de 1989.

El recién electo presidente de Brasil, el mayor país de nuestra América Latina, afirmaba: xnuestra propuesta parte de que no se trata de saber cuánto será posible crecer después de haber pagado la deuda, sino de saber cuánto se puede pagar después de haber garantizado nuestro crecimiento." El candidato perdedor, Da Silva («Lula») afirmaba: «que se entienda que este problema ha sido responsable por más muertos en un mes que la guerra Irán-lrak en 7 años» (1).

Para los obispos estadounidenses, "una ética fundamental de la comunidad hebrea antigua fue el justo tratamiento de las viudas y huérfa* nos. El carácter moral de una sociedad habia de medirse por la forma en que cuidaba de sus miembros más vulnerables. Hoy los niños del tercer mundo son los huérfanos de la crisis de la deuda y sus madres son las viudas. Su desnutrición, pobreza y muertes prematuras impugnan los patrones de interdependencia dentro y entre los paises que han producido la crisis" (2).

Los hechos brutos son: en cinco años (1982-1987) América Latina trans-

" Director de "Instituto Latinoamericano de Doctrina y Estudios Sociales" (ILADES), San" tiago de Chile.

(1) Entrevistas al Diario «La Epoca», Santiago de Chile, 14 y 15 de noviembre de 1989.

(2) Alivio de la deuda externa. United States Catholic Conference Washington D. C., septiembre de 1989) N. ${ }^{\circ} 30$. 
Mario Zañartu, S.J.

firió 150.000 millones de dólares (dos veces el plan Marshall para la Europa de la post-guerra) y la deuda creció en 80 mil millones de dólares, pasando de 330 mil a 410 mil millones de dólares (3).

Los fríos y recientes comentarios de la CEPAL para la región muestran la misma gravedad del problema: «el crecimiento de la inflación que ha afectado a los paises de América Latina en esta década, es atribuible no sólo a los defectos de la política económica, sino también el estrechamiento de los espacios libres de estos paises, debido a la reversión en la transferencia de recursos externos, en la cual la deuda externa juega un rol fundamental. Esta reversión no sólo requiere un mayor excedente comercial sino que ha traido consigo normalmente una transferencia de recursos desde el sector privado hacia el sector público y en su ausencia un creciente déficit fiscal. Muchos países han tenido dificultades en movilizar... Por lo tanto han tenido que recurrir al préstamo, doméstico o, si el mercado de capital no es suficientemente grande como para esto, simplemente a imprimir más dinero generando presiones inflacionarias" (4).

Si comparamos las cifras porcentuales de la transferencia de intereses y utilidades con respecto al producto doméstico bruto con la llegada de capital neto, tenemos que en el período 1973-1981 el primero fue -2.9 por $100 \mathrm{y}$ el segundo 5.5. por 100, dejando un total neto positivo de 2.7 por 100 . En cambio en $1982-1988$ el primero fue de -5.3 por 100 y el segundo de 1.4 por 100, dando esto una transferencia (negativa) de -4.0 por 100 en 1988 la situación se agravó, siendo el primero -4.7 por 100 y el segundo 0.4 por 100 , lo que dejó una transferencia neta de -4.3 por 100 .

La causa de esta desastrosa situación es en parte atribuida al F.M.l. por las condiciones que impone a la reestructuración de la deuda. Las condiciones del fondo están orientadas unilateralmente hacia la importación, la administración de dinero, la limitación de la función social del Estado, la disminución del salario real de la mayoria de la población con el fin de obtener mejores oportunidades de ganancias para la inversión prí. vada y para la exportación. Las consecuencias son un serio deterioro de las condiciones de vida del pueblo común, un crecimiento del desempleo, una disminución de la producción y crecimiento de la dependencia del crédito externo, imposibilttando el pago de la deuda a partir de las ganancias de la exportación (5).

El juicio que sobre este telón de fondo dan los obispos estadounidenses es lapidario: «creemos que el problema de la deuda, con sus conse-

(3) Datos de CEPAL.

(4) Economic Panorama of Latin América 1989 (Economic Commision for Latin Amer: ca and the Caribean. United Nations; Santiago, Chile, september 1989). Pág. 8

(5) Cfr. Hengsbach S. J., Friedhelm, "Deuda Externa", en Promotio Justitiae (Roma) N. ${ }^{\circ} 42$, octubre, 1989 , págs. 89. 


\section{La deuda externa y los pobres}

cuencias humanas, es económicamente insostenible, políticamente peligroso y éticamente inaceptables (6).

Entre estos hechos los obispos mencionan los disturbios por alimentos en Argelia, resultantes de los acuerdos de reestructuración de la deuda; las muertes producidas en los disturbios del sur de Jordania, ocasionados por los aumentos de precio debido a una reprogramación de la deuda con el Fondo; los disturbios en la República Dominicana, en Egip. to y en Zambia debido a los aumentos de precio de los alimentos; el estado de asedios que existió en Argentina para reducir la violencia provocada por las medidas de la autoridad; y las más de 300 muertes en Venezuela durante una semana de violencia que siguió a la imposición de similares medidas de la autoridad por el nuevo presidente, a fin de ayudar a atender el servicio de la deuda.

\section{PROCESO ECONOMICO DE GENERACION DE LA DEUDA EXTERNA (7)}

1. Un gobierno o privados venden pagarés a gobiernos privados de otros paises. Esto genera posibilidad de injusticia en el precio, sobre todo en las condiciones de pago.

2. El gobierno o los privados usan ese ingreso: depositándolo en el extranjero, consumiéndolo o invirtiéndolo.

3. El gobierno o privados tienen que rescatar los pagarés según pactado con ingreso proveniente de: la inversión generada por el préstamo, nuevos préstamos, o ingreso ajeno generado por impuestos o inflación.

4. Las injusticias pueden provenir de:

a) Precio injusto o que se hace injusto por cambio de situaciones;

b) Gasto de invertido, o invertido no eficazmente, o distribución injusta de los resultados de la inversión;

(6) Op. cit. pág. 6 .

(7) Para un tratamiento más científico del problema, se pueden consultar:

- Chien Nan Wang, "El costo del incumplimiento y los préstamos internacionales", en Economic Commentary (Banco de la Reserva Federal de Cleveland).

- Feinberg, Richard E., The Intemperate Zone: The Third World Challenge to U. S. Foreing Policy (Richard Feinberg ed.).

- Frydl, Edward. . y Sobol, Dorothy M., «Perspectivas para ef manejo de la Deuda de los Paises Menos Desarrollados: Redacción contra Condenación de la Deudaw, trabajo presentado a la reunión anual de la American Economic Association.

- Mundel. Robert A., Deuda Latinoamericana y el problema de las Transterencias.

- Sjaastad, Larry A., Debt, Depression and Real Rates of Interest in Latin America.

(Se puede encontrar un resumen del aporte de estos attores en la revista «perspectivas Económicas", U. S. Information Agency, Washington D. C., N. ${ }^{\circ} 68$. 
Mario Zañartu, S.J.

c) Pago a costa de todos, pero no proporcional al beneficio obtenido.

\section{LOS CRITERIOS DE LA INJUSTICIA}

1. El comercio internacional es ciertamente bueno cuando es bueno para las partes implicadas y no daña al resto.

2. La exportación de pagarés y su posterior rescate, es ciertamente buena cuando es buena para las partes implicadas y no daña al resto.

3. El bien que se pretende es el bienestar de la comunidad a la larga y en su conjunto. El medio al que se recurre es la obtención ahora de recursos que se devolverán después en el caso del deudor; y la transferencia ahora de recursos que se recuperarán después en el caso del acreedor. Pero la búsqueda de este bien puede generar males.

4. Este intercambio es posible sólo sobre la base de credibilidad de las promesas de las partes. Las rupturas son un mal: «Se trata también de evitar las suspensiones de pagos susceptibles de hacer vacilar el sistema financiero internacional con riesgo de provocar una crisis generalizada. Una ética de supervivencia debe guiar asi los comportamientos y las decisiones; evitar las rupturas entre acreedores y deudores y las denuncias unilaterales de compromisos anteriores»; nos afirma la Comisión Pontificia Justicia y Paz en su documento sobre el problema, emitido el año $1987(8)$.

5. La transferencia neta de recursos de los deudores (normalmente paises en desarrollo) a los acreedores (normalmente ricos) es un mal social.

6. También es un mal social que estos recursos sean sustraídos de los más pobres.

7. Son los corresponsables de la situación quienes deben asumir su responsabilidad que los males generados no sean desproporcionalmente contraproducentes.

8. Nunca un mal debe ser directamente querido. Sólo se quiere un bien. Pero no hay actos o actitudes que de alguna manera no generen algún inconveniente; no hay crecimiento sin ahorro y no hay ahorro sin restricciones. No se busca directamente la restricción, sino el crecimien. to; pero éste generará restricciones. Seria injusto que el mal generado fuese desproporcionadamente contraproducente. Pero antes de ese punto hay una gama de soluciones que serían justas.

(8) Pontificia Comisión Justicia y Paz, uAl Servicio de la Comunidad Humana una consideración ética de la deuda externa internacionalı, en DOCLA (1LADES; Santiago de Chile, $N .90$ ), pág. 9 


\section{La deuda externa y los pobres}

9. La pregunta ética no es ¿cuántos Jumbos sería proporcionado sacrificar para preservar las ventajas del funcionamiento del mercado internacional?, sino ¿qué restricciones y a quiénes se le pueden exigir para que el bienestar de la humanidad, a la larga y en su conjunto, se beneficie del comercio internacional?

\section{LOS CORAESPONSABLES}

Uno de los corresponsables es ciertamente el deudor. Los obispos mexicanos nos testimonian que la opinión pública mejicana continuamente expone su sospecha y, en algunos casos, su certeza, de que hay una relación entre la corrupción y el endeudamiento en México; dicen: "es importante que se dé una información clara acerca de fortunas inexplicables de personas del sector público y del privado. La crisis de valores morales se agrava cuando se dejan sin respuesta estas inquietudes, porque surge espontánea la convicción de que hay complicidad y de que en nuestra sociedad es favorecido el robo a la nación. Nadie ignora que en el deterioro de nuestra vida nacional, ocupa un lugar importante la práctica de la corrupción.

Los problemas que plantea la deuda externa encuentran un obstácu. lo para su solución en la fuga de capitales y en el contrabando. Estos vicios ponen al descubierto el enorme egoismo de quienes quieren al pais sólo para sus propios intereses y poco o nada hacen por el bien de todoss (9).

Por el lado del acreedor se puede pedir, como lo hacen los obispos estadounidenses a su gobierno, que se perdone la deuda de los paises africanos al Sur del Sahara, y al Congreso de EE.UU. que facilite fondos si se requieren para permitir seguir adelante con esta iniciativa; piden también los obispos al presidente y al Congreso, que se adopten las medidas apropiadas como las sugeridas por el secretario de Hacienda Brady, para modificar disposiciones de la deuda que redundan en el interés de todas las partes (10).

También piden a las instituciones crediticias comerciales y banqueros que comprendan y acepten la corresponsabilidad para solucionar este problema. Los obispos de EE. UU. se dirigen sobre todo a los banqueros católicos, mostrándoles que ésta no es una cuestión de lo que se denomina "caridad" sino un asunto de justicia, y afirman que la justicia no es ni sen-

(9) Conferencia Episcopal de México, «La deuda externa», en DOCLA Op. cit. pág. 18. (10) Alvio de la deuda externa. Op cit. N. ${ }^{\circ} 52-53$. 
Mario Zañartu, S.J.

timental ni optativa, que es realista y es obligatoria. Dicen que la corresponsabilidad de los banqueros tampoco es optativa (11).

También piden a las agencias multilaterales, sobre todo el Banco Mundial y al F.M.I. que, como corresponsables, diseñen politicas crediticias más a tono con un desarrollo equitativo en el tercer mundo; piden una verdadera flexibilidad y un enfoque caso por caso con los diferentes palses que tienen circunstancias muy diferentes en vez de la condicionalidad rígida y uniforme con la cual el Banco Mundial y el Fondo Monetario parecen estar en realidad comprometidos (12).

Los obispos estadounidenses piden incluso que las cartas estatutarias que rigen al Fondo Monetario y al Banco Mundial y a los Bancos regionales sean modificadas en caso de constituir un obstáculo a su participación en planes eficaces de reducción de la deuda. Los obispos, incluso, piden a los representantes de su pais en las juntas directivas de estas instituciones, que inicien acción a fin de suprimir o modificar aquellos párrafos de los estatutos que impiden la acción recomendada (13).

Entre los corresponsables el gran ausente es la comunidad internacional. Esta no existe, porque no existe autoridad internacional propiamente tal. Se dan, sin embargo, esfuerzos suplentes que al interior de los paises son los políticos, cuya especialidad es el Bien Común; los sindicalistas, cuya especialidad es el bien de los pobres; y las Iglesias, cuya especialidad es el bien integral del hombre.

A nivel internacional también se dan los mismos estorzados suplentes: las internacionales políticas, los internacionales sindicales y las Igle-
sias universales.

\section{LAS PROPUESTAS}

Las soluciones al problema expuesto deben obedecer a los siguientes criterios de justicia, solidaridad y bien común:

a) El objeto primordial debe ser revitalizar las economías y ayudar más a los pobres;

b) El presupuesto es que los Derechos Humanos de las personas y la autonomía del país.deudor sean respetados:

c) La responsabilidad debe ser compartida, sobre todo por los segmentos más ricos a nivel interno o entre paises;

\footnotetext{
(11) Ibidem, N. 56

(12) Ibidem. N. ${ }^{\circ} 54$.

(\$3) Ibidem, N. 55
} 


\section{La deuda externa y los pobres}

d) Debe disminuir la deuda neta;

e) Debe haber un beneficio inmediato para los pobres del pais deudor;

f) Hay que tomar en cuenta el desempeño de los reponsables del pais deudor. Vale decir, la forma en que ellos responden ante su pueblo y la forma en que se promueven y protegen los derechos humanos; los fines para los que se obtuvieron los préstamos; cómo se utilizaron y qué clase de estuerzo se está haciendo para promover el desarrolio y para reembolsar los préstamos;

g) Debe haber alivio de los factores externos al deudor: equidad y justicia de la economía mundial;

h) Hay que realzar la capacidad del pais deudor para promover un desarrollo independiente, autónomo, participativo y sostenible.

Estos son los criterios que desarrollan los obispos estadounidenses en su documento (14), y por ellos deben regirse las acciones correctoras.

\section{La esperanza de la Santa Sede}

En su discurso a la Asamblea General de la FAO en noviembre de 1987. el Papa Juan Pablo II manifiesta: «La Santa Sede nutre ciertamente la esperanza de que como resultado de un creciente sentido de responsabilidad y solidaridad entre las naciones del mundo, se realizarán mayores esfuerzos para establecer unas relaciones internacionales y una ayuda internacional basados en principios de auténtica justicia y respeto mutuo.»

Y concluye con la esperanza de: «Que toda la comunidad internacional se haga cada vez más sensible a las necesidades de los pobres y de los que sufren hambre en el mundo, y que comprenda que la acción coordinada por parte de todos no debe ser ya más retrasada (15).»

Santiago, diciembre de 1989

(14) Cir. lbidem, N. ${ }^{44}$.

(15) Cir. DOCLA, N. ${ }^{\circ} 92$, págs. 10 y 11 